\title{
REVIEW ARTICLE Molecular mechanisms of cortical differentiation
}

\author{
Francois Guillemot, ${ }^{1}$ Zoltán Molnár, ${ }^{2}$ Victor Tarabykin ${ }^{3}$ and Anastassia Stoykova ${ }^{4}$ \\ ${ }^{1}$ Division of Molecular Neurobiology, National Institute for Medical Research, The Ridgeway, Mill Hill, NW7 1AA London, UK \\ ${ }^{2}$ Department of Physiology Anatomy and Genetics, Le Gros Clark Building, University of Oxford, Oxford, OX1 3QX, UK \\ ${ }^{3}$ Department of Molecular Biology of Neuronal Signals, Max-Planck Institute for Experimental Medicine, 37075 Göttingen, Germany \\ ${ }^{4}$ Department of Molecular Cell Biology, Max-Planck Institute for Biophysical Chemistry, 37077 Göttingen, Germany
}

Keywords: corticogenesis, molecular markers, neurons, Ngn, Pax6

\begin{abstract}
During development, several populations of progenitor cells in the dorsal telencephalon generate a large variety of neurons which acquire distinct morphologies and physiological properties and serve distinct functions in the mammalian cortex. This paper reviews recent work that has identified (i) key molecules involved in the specification and differentiation of cortical neurons, (ii) novel genes which distinguish distinct subsets of cortical progenitors and may be involved in the diversification of cortical neurons present in different cortical layers, and (iii) mechanisms involved in the generation of different projection neuronal subtypes in the well-studied model of layer 5 of the rodent cortex.
\end{abstract}

\section{Introduction: neurogenesis and gliogenesis} in cerebral cortex

All neurons, astrocytes and oligodendrocytes which form the adult nervous system originate ultimately from progenitor cells located in the ventricular zone of the embryonic neural tube. The cerebral cortex is composed of two main populations of neurons, projection (or pyramidal) neurons which are glutamatergic and excitatory, and interneurons which are GABAergic and inhibitory. Cortical projection neurons originate from progenitors located in the cortical ventricular zone. In contrast, most, if not all, cortical interneurons originate from progenitors located outside the cortex and primarily in the ventral telencephalon, at least in rodents (Marin \& Rubenstein, 2001; Gorski et al., 2002). Following their birth in the ventral telencephalon, interneurons use multiple and complex routes of tangential migration to reach their final position in the developing cortex (Marin \& Rubenstein, 2001). Importantly, a significant fraction of GABAergic interneurons appear to be generated in the cortex in humans (Letinic et al., 2002).

Cortical astrocytes, like projection neurons, originate from progenitors located in the cortex. Retrovirus-based lineage studies and in vitro culture experiments have shown that, early in cortical development, some of the progenitors located in the ventricular zone (VZ) are multipotent stem cells which generate both projection neurons and astrocytes (Davis \& Temple, 1994; Williams \& Price, 1995; Temple, 2001). These multipotent progenitors initially expand via symmetric divisions, but they soon generate more restricted progenitors, including neuronal- and astrocyte-restricted progenitors, which predominate during the later part of corticogenesis (Luskin et al., 1988; Price et al., 1995; Reid et al., 1995; Williams \& Price, 1995; Nieto et al., 2001; Temple, 2001). Restricted neuronal and glial

Correspondence: Dr Anastassia Stoykova, as above.

E-mail: astoyko@gwdg.de

Received 5 October 2005, revised 1 December 2005, accepted 1 December 2005 progenitors have also been reported at very early stages of cortical development, raising the possibility that not all cortical neurons and glia originate from multipotent stem cells (Davis \& Temple, 1994; McCarthy et al., 2001).

As in the rest of the nervous system, neurons in the cortex are born and differentiate before astrocytes (Bayer \& Altman, 1991). This is due to the sequential generation of neuronal and astrocyte precursors (Qian et al., 2000) as well as to the delayed differentiation of astrocyte precursors, a process which involves multiple signalling, transcriptional and epigenetic mechanisms which are beginning to be elucidated (Morrow et al., 2001; Sun et al., 2001; Fan et al., 2005; He et al., 2005).

The origin of cortical oligodendrocytes is more complex than that of cortical astrocytes. During embryonic development, oligodendrocyte precursors in the telencephalon are thought to be generated outside the cerebral cortex, from stem cells located in the ventral telencephalon which also generate GABAergic interneurons (He et al., 2001; Ross et al., 2003). Like interneurons, oligodendrocyte precursors then migrate tangentially into the developing cortex (Thomas et al., 2000; Tekki-Kessaris et al., 2001). Fate-mapping of cortical progenitors in the mouse, however, indicates that many oligodendrocytes in the adult cortex originate from cortical progenitors (Gorski et al., 2002). Indeed, a second postnatal wave of oligodendrocyte progenitors, which in contrast with earlier embryonic ones are glial-restricted, has been reported in the postnatal cortical subventricular zone (Ivanova et al., 2003; Marshall et al., 2003).

The rest of this review will focus on the generation of pyramidal neurons by cortical progenitors. The generation of new neurons is a complex process which involves a number of tightly coordinated steps, including the commitment of multipotent stem cells to a neuronal rather than a glial fate, the arrest of progenitor divisions, the acquisition of differentiated features by postmitotic precursors, including the growth of axons and dendrites, and the migration of 
nascent neurons outside the germinal zone towards a particular laminar position in the cortical plate. Important progress has been made in recent years in identifying some of the regulatory mechanisms involved. Proneural genes in particular have been shown to regulate many aspects of neurogenesis and, therefore, to play a central role in orchestrating the neurogenic process.

\section{Regulation of the core programme of neurogenesis Proneural genes}

Proneural genes encode typical basic helix-loop-helix (bHLH) transcriptional activators, which heterodimerize with ubiquitously expressed bHLH partners called E proteins, and bind specific 6-bp motifs called E boxes. Binding of proneural E protein dimers to $\mathrm{E}$ boxes present in the promoter of target genes results in transcription activation. Although very few of their direct transcriptional targets have yet been reported, the biological activity of proneural proteins has been analysed in some detail in multiple model organisms, where they have been shown to play a critical role in neurogenesis (reviewed in Brunet \& Ghysen, 1999; Bertrand et al., 2002). In vertebrate embryos, a combination of gain-of-function and loss-of-function experiments have led to the idea that expression of proneural proteins in stem cells is both necessary and sufficient to promote the generation of postmitotic neurons and, therefore, that proneural proteins regulate the key steps of commitment of stem cells to the neuronal fate, cell cycle exit and initiation of a neuronal differentiation programme (Bertrand et al., 2002).

Three proneural genes are expressed in the cerebral cortex of the mouse, Neurogenin1 (Ngn1), Neurogenin2 (Ngn2), and Mash1 (Fode et al., 2000; Nieto et al., 2001), but Ngn2 is clearly the most important of the three genes for corticogenesis. Only Ngn2 mutants present a distinct corticogenesis defect (Fode et al., 2000; Nieto et al., 2001), and Ngn2 is involved in regulating Ngn1 (positively) and Mash1 (negatively) in cortical progenitors, while the converse is not true (Fode et al., 2000).

\section{Neuronal commitment}

The function of proneural genes in cortical development has been studied by analysis of mouse null mutants (Fode et al., 2000; Nieto et al., 2001; Schuurmans et al., 2004), and by overexpression in dissociated cultures (Sun et al., 2001).

A severe loss of proneural protein activity is observed in mice mutant for both $N g n 2$ and Mash1, in which the cortex only retains residual expression of the third proneural gene $\mathrm{Ngn} 1$, which requires Ngn2 for its normal expression (Fode et al., 2000; Nieto et al., 2001). In these mice, cortical neurogenesis is much reduced, as measured by expression of a neuronal precursor marker, NeuroD, and the size of the cortical plate (CP). Notch signalling, as measured by expression of Hes5, is also affected. Clonal culture experiments have shown that this neurogenesis defect is due to a loss of neurogenic progenitors in Ngn2;Mash1 double-mutant cortex. Strikingly, this loss is associated with a compensatory increase in the number of astrocytic progenitors and progenitors which remain bipotent, thus demonstrating that proneural proteins are normally required to promote the choice of a neuronal fate, and inhibit the alternative astrocytic fate, in bipotent cortical stem cells (Nieto et al., 2001).

Analysis of Ngn1 activity in progenitor cultures has confirmed that this proneural protein has a dual function of promotion of neurogenesis and inhibition of astrogenesis, and has provided evidence that distinct mechanisms may underlie each of these functions (Sun et al., 2001). While the neurogenic activity of Ngn1 requires an intact DNA binding domain and therefore involves the conventional transcriptional activation of target genes, such as the neuronal differentiation gene NeuroD, the antiastrogliogenic activity involves a novel mechanism which does not require DNA binding of Ngn1 but instead requires interaction of Ngn1 with intracellular components of several signalling pathways. Astrocyte differentiation, as measured by expression of the astrocytic marker GFAP, requires the synergistic activity of two signalling pathways, BMP-Smad and LIF-CNTF-JaK-STAT (Nakashima et al., 1999). Ngn1 has been shown to block the activity of Smad1 downstream of BMP, by sequestering a Smad1/P300 complex, and to interfere with the activation of STAT1 and STAT3 by LIF/CNTF (Sun et al., 2001). A similar phenotype of reduced neurogenesis and premature or excessive astrogenesis has been observed in other brain regions in different proneural mutants (Tomita et al., 2000; Parras et al., 2004), suggesting that the neuronal commitment of bipotent neuronal-glial progenitors is a general and essential aspect of the function of proneural proteins.

\section{Cell cycle exit}

Cell cycle exit is an essential step in the progression of neuronal lineages, and is tightly coupled to specification of progenitors to a particular neuronal identity (which usually occurs during the last cycle; McConnell, 1995) and to the initiation of a differentiation programme (usually after cell cycle exit; Edlund \& Jessell, 1999).

In a number of tissues, including muscles and endocrine cells, bHLH genes are part of the coupling mechanism, simultaneously promoting the differentiation of progenitors and their cell cycle exit, the later activity involving the regulation of cell cycle genes such as cyclin-dependent kinase inhibitors (Halevy et al., 1995; Mutoh et al., 1998). A similar role of proneural bHLH genes in promoting cell cycle exit has been reported in various parts of the nervous system, including peripheral ganglia (Lo et al., 2002) and the spinal cord (Mizuguchi et al., 2001), and this activity probably also involves the activation of cyclin-dependent kinase inhibitors, in particular p27/Kip1 (Farah et al., 2000). Regulation of cell cycle progression and cell cycle length is a crucial process in corticogenesis and determines the total number of cortical neurons produced, as well as the relative ratios of neurons present in different cortical layers (Caviness et al., 2003; Polleux et al., 1997; Lukaszewicz et al., 2005). The contribution of proneural genes to the regulation of cell cycle arrest by cortical progenitors has not been directly examined.

Two main populations of cortical progenitors contribute to the generation of cortical projection neurons, radial glial cells in the VZ, which possess a ventricular process and divide at the ventricular (apical) surface, and basal or nonsurface progenitors in the subventricular zone (SVZ), which originate from radial glial cells (or earlier from neuroepithelial cells), have lost their ventricular attachment and divide at a distance from the ventricle (Haubensak et al., 2004; Miyata et al., 2004; Noctor et al., 2004). Indirect evidence from ectopic expression experiments by retrovirus infection of cortical slices suggests that Ngn2 influences the mitotic behaviour of cortical progenitors, converting surface-dividing cells (radial glial cells) into non-surface-dividing cells (basal progenitors) rather than promoting outright cell cycle withdrawal (Miyata et al., 2004). Further studies are required to elucidate the mechanism of coupling of cell cycle exit and differentiation of cortical progenitors, and the contribution of proneural genes to this mechanism. 


\section{Neuronal differentiation}

Throughout the nervous system, proneural genes appear to be the main determinants of neuronal differentiation. Ectopic expression of a proneural gene is usually sufficient to initiate a full neuronal differentiation programme in undifferentiated neural progenitor cells (Ma et al., 1996; Farah et al., 2000; Mizuguchi et al., 2001). Little is known about the individual genes that contribute to the generic programme of neuronal differentiation (i.e. the programme regulating the acquisition of features common to all neurons, such as the growth of axon and dendrites, as opposed to subtype-specific differentiation programmes, discussed in the next section). The best candidate 'neuronal differentiation genes' encode transcription factors which, like proneural proteins, belong to the bHLH class, in particular NeuroD1 (Lee, 1997). These bHLH neuronal differentiation genes are sequentially expressed as neurons differentiate, and this regulatory cascade is activated by proneural genes in many regions of the nervous system (Bertrand et al., 2002).

The contribution of proneural genes to the generic aspect of neuronal differentiation in the cortex has been difficult to assess from the analysis of proneural mouse mutants. This is due to the fact that loss of proneural activity in $\mathrm{Ngn2;}$ Mash1 double-mutant mice results in a defect in neuronal commitment upstream of the neuronal differentiation programme (see above), while Ngn2 single-mutants present a defect in specification of cortical neuron identity but no overt differentiation defect, due to compensation by up-regulation of Mash1 (Fode et al., 2000; Schuurmans et al., 2004; see below). Nevertheless, mutant analysis has shown that $\mathrm{Ngnl}$ and -2 are required for normal expression in the cortex of many bHLH genes that are sequentially expressed in differentiating cortical neurons and are probably involved in their differentiation, including NeuroD1, NeuroD2, Math2, Math3 and Nscll (Schuurmans et al., 2004). Moreover, other regulatory genes that are similarly sequentially expressed in cortical neurons and implicated in their differentiation, including the T-box genes Tbrl and Tbr2 (Hevner et al., 2001; Englund et al., 2005) also depend on the function of $\mathrm{Ngnl}$ and -2 for their normal cortical expression (Schuurmans et al., 2004). However, all the bHLH and $\mathrm{Tbr}$ differentiation genes regulated by $N g n 1$ and -2 in the cortex are restricted to cortical progenitors and/or neurons in the embryonic telencephalon, and are not expressed by subcortical or basal ganglia progenitors and neurons (Schuurmans et al., 2004). It is therefore unclear whether these genes are part of a generic neuronal differentiation programme or instead contribute to a regional differentiation programme involved in the acquisition of unique features of cortical projection neurons. Further analysis of the differentiation programmes of telencephalic neurons, and identification of their generic and subtype-specific components, is required to clarify the contribution of proneural genes to the differentiation of cortical neurons.

\section{Specification of cortical neuron identity}

The mechanisms underlying the specification of neuronal identity have been explored in a number of invertebrate and vertebrate systems. In mammals, specification of both spinal motor neurons and retinal neurons, among the best-studied models, involves a cooperation between neural bHLH genes and homeodomain genes (Lee \& Pfaff, 2003; Hatakeyama \& Kageyama, 2004). Both proneural bHLH genes (Bertrand et al., 2002) and homeodomain genes (Shirasaki \& Pfaff, 2002) have also been separately implicated in the specification of a large variety of neuronal types. Cortical neurons are no exception, and the proneural genes NgnI and -2 and the homeodomain gene Pax6 have been shown to have an important role in specification of several aspects of the phenotype of cortical projection neurons.

\section{Role of $\mathrm{Ngn} 1$ and -2}

Ngnl and -2 and Mash1 have largely complementary expressions in the telencephalon, in cortical progenitors and basal ganglia progenitors, respectively, raising the possibility that these genes contribute to the specification of the distinct neuronal fates of these two progenitor populations (Fode et al., 2000). A combination of loss-of-function and gain-of-function studies has confirmed this hypothesis, demonstrating that NgnI and -2 act as selector genes in cortical progenitors to regulate a binary choice between two distinct and alternative regional differentiation programmes. In wild-type mice, expression of $\mathrm{Ngnl}$ and -2 in dorsal telencephalic progenitors activates a programme that provides neurons with a glutamatergic neurotransmission phenotype (marked by expression of vesicular glutamaterigc transporters vGlut1 and -2) and a cortical regional character (marked by expression of genes such as NeuroD1 and -2, Math2 and Tbrl and -2; see above). In Ngn1-Ngn2-mutant mice, a large fraction of dorsal telencephalic progenitors activate instead a programme conferring on neurons a GABAergic phenotype (marked by expression of the biosynthetic genes GAD1 and GAD2 and of GABA transporters) and a basal ganglia regional character (marked by expression of the $D l x$ family of homeodomain genes; Schuurmans et al., 2004). This role of Ngn 1 and -2 in selecting the regional and neurotransmission identity of cortical neurons appears to involve several parallel activities. Mash1 is de-repressed in Ngn1- and Ngn2-mutant cortex, suggesting that at least part of the function of $N g n 1$ and -2 in specification of cortical neurons may involve repression of Mash1 and the Mash1induced basal ganglia programme. Indeed, many of the basal gangliaand GABAergic-specific genes ectopically activated in Ngn 1- and Ngn2-mutant cortex remain low in Ngn2;Mash1 double-mutant mice, indicating that $\mathrm{Ngnl}$ and -2 repress the basal ganglia differentiation programme in part via repression of Mash1. In contrast, cortical and glutamatergic-specific genes fail to be activated in both Ngn2 singleand Ngn2;Mash1 double-mutant cortices, indicating that Ngn2 also directly activates the cortical glutamatergic programme, independently of Mash1 regulation (Schuurmans et al., 2004; see also Fig. 1).

$\mathrm{Ngn} 2$ specifies other properties of cortical projection neurons including their characteristic unipolar dendritic morphology, which gives them their 'pyramidal' shape (Hand et al., 2005). Interestingly, this activity requires phosphorylation of a tyrosine residue in the C-terminal part of Ngn2, which is only present, among Neurogenin proteins, in mammalian Ngn2, suggesting that it is part of an evolutionarily recent mechanism regulating cortical neuron specification. The signalling cascade involved in Ngn2 phosphorylation in the cortex is presently unknown.

Importantly, Ngn1 and -2 do not appear to be involved in specification of all cortical neurons. In Ngn1 and -2 mutants, neurons born during the first part of corticogenesis [embryonic day (E)11.5E14.5] are misspecified, but neurons born later (E14.5-E17.5) normally express cortical and glutamatergic markers. In keeping with this finding, Ngn2 single-mutants, analysed after birth when cortical layers can be distinguished, present defects in expression of laminarspecific markers in early born neurons in layers 6 and 5, while lateborn neurons in layers 4 and 2/3 appear normal (Schuurmans et al., 2004). This result suggests that distinct determinants regulate the specification of early-born and late-born neurons, including for the acquisition of pan-cortical properties such as glutamatergic neurotransmission. Among the candidate regulators of late-born cortical neuron identity is the paired-homeodomain factor Pax6. Pax6 plays 

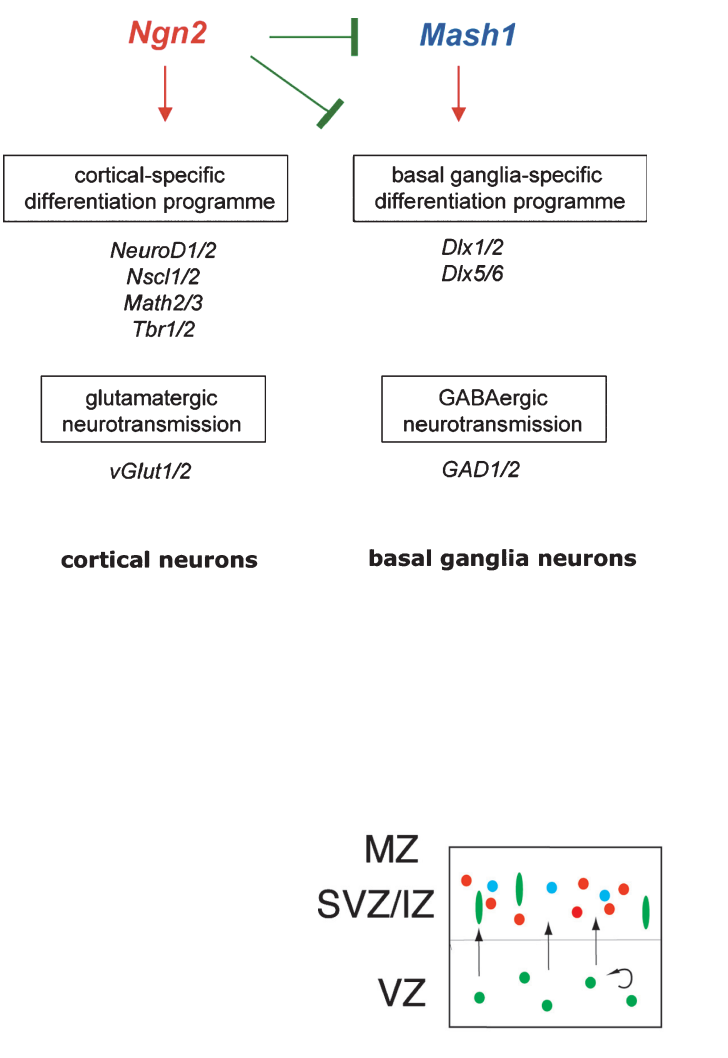

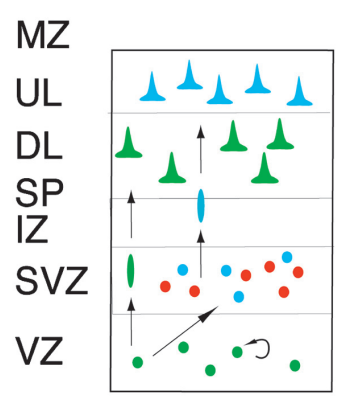

FIG. 1. Model of the genetic programmes controlling neuronal specification in the mouse telencephalon. The proneural genes Ngn1, Ngn2 and Mash1 are involved in the specification of cortical neurons and basal ganglia neurons, respectively, by coordinatedly regulating several aspects of their identity, including their regional identity and neurotransmission phenotype. Some of the genes involved in region-specific differentiation and neurotransmission in cortical and basal ganglia neurons, which are regulated by $N g n 1$ and -2 and by Mash1, respectively, are listed. See text and Schuurmans et al. (2004) for further details.

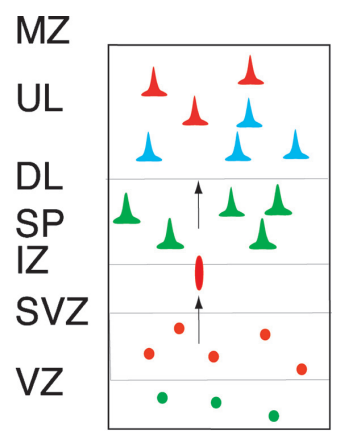

FIG. 2.

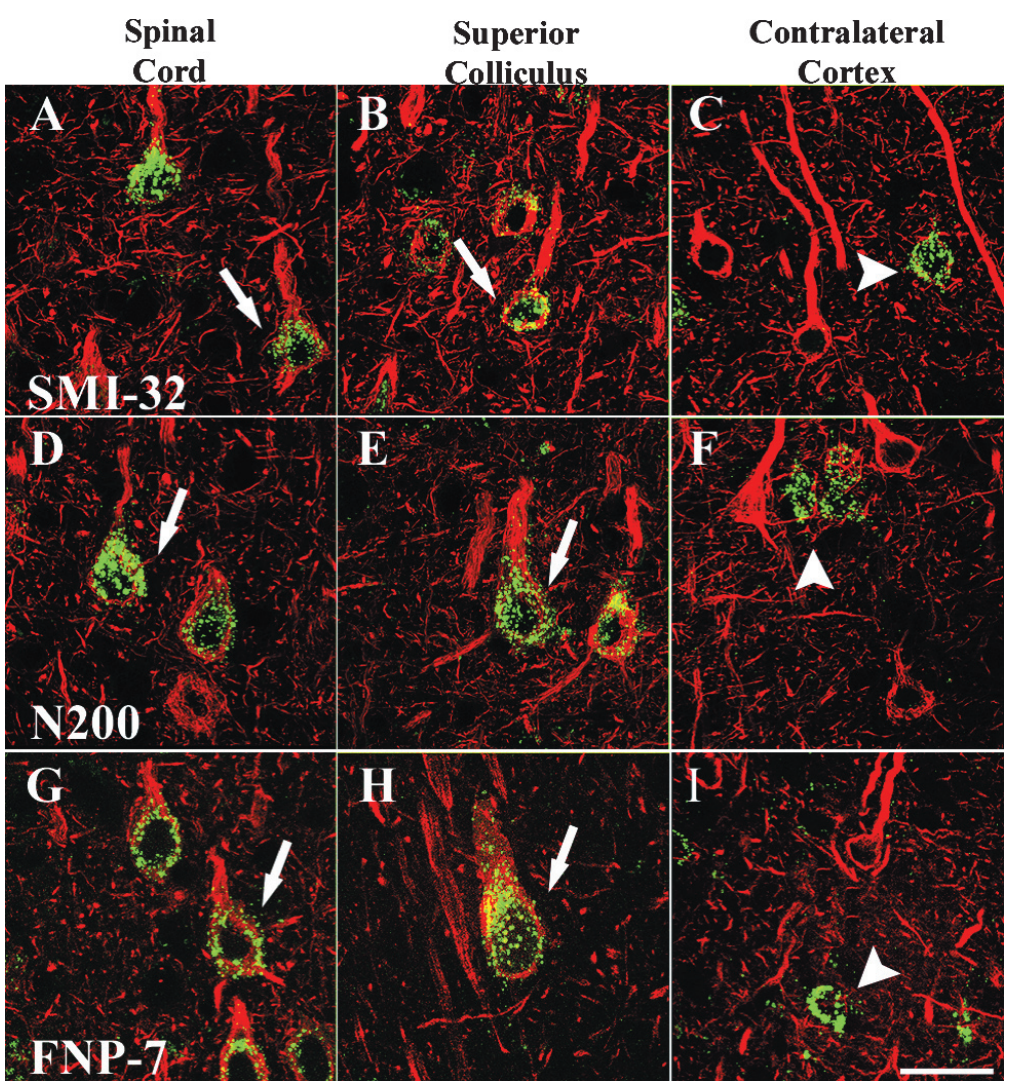

FIG. 3.

(c) The Authors (2006). Journal Compilation (c) Federation of European Neuroscience Societies and Blackwell Publishing Ltd European Journal of Neuroscience, 23, 857-868 
multiple roles in development of the cerebral cortex (see below). Some of these functions are probably mediated by Ngn2, particularly during early phases of cortical development, as Pax6 is a direct transcriptional regulator of Ngn2 in cortical progenitors (Scardigli et al., 2003).

\section{Transcription factor Pax6 in cortical specification}

Pax6 is a member of the evolutionarily conserved Pax family of transcriptional regulators with a restricted expression in the developing CNS and the eye (Walther \& Gruss, 1991; reviewed by Simpson \& Price, 2002). Pax6 contains two DNA binding domains, the paired domain and the paired-type homeodomain (Bopp et al., 1986; Treisman et al., 1991). In vertebrates, alternative splicing generates two isoforms: the canonical Pax6 and the Pax6-5a isoform, where an insertion of 14 amino acids into the paired domain changes the binding properties of the Pax6-5a isoform (Czerny et al., 1993; Epstein et al., 1994).

\section{Pax6 in the regional patterning of the telencephalon}

Pax6 is a pattern-forming gene involved in the dorsoventral specification of telencephalic progenitors. As early as E9.0, Pax6 shows a regionalized expression confined to the neuroepithelium of the dorsal part of the telencephalic primordium or pallium, the anlage of the future cortex (Walther \& Gruss, 1991; Stoykova \& Gruss, 1994; Stoykova et al., 1997). Only one active allele of the homeoboxcontaining genes Pax6 or Emx2 is sufficient to promote the morphogenesis of the cerebral cortex, indicating that these two genes act in parallel to induce corticogenesis (Muzio et al., 2002b). In the absence of Pax6 and Emx2 function, pallial neuroblasts are converted into subpallial neuroblasts which accumulate in an aberrant structure resembling basal ganglia (Muzio et al., 2002b). In the cortical primordium, the early expression of Pax 6 and the homeobox gene Gsh2 outline the anlagen of the pallium and subpallium, respectively, and cross-repressive interactions between these two genes establish the pallial-subpallial border (PSPB) (Toresson et al., 2000; Yun et al., 2001). Disruption of the PSPB in the Pax6-Small eye mutant, where Pax6 is not functional (Hill et al., 1991), permits more cells to migrate from the subpallium into the cortex (Chapouton et al., 1999). A number of studies have demonstrated striking specification defects in the telencephalic neuroepithelium of homozygous Small eye (Sey/Sey) embryos, with a dorsal shift of subpallial markers, initially limited to the ventral and the lateral pallium, but later spreading progressively into the VZ of the entire pallium (Stoykova et al., 1996, 2000; Toresson et al., 2000; Yun et al., 2001; Muzio et al., 2002a; Kroll \& O'Leary, 2005). Because Ngn2 is a direct downstream target of Pax6 (Scardigli et al., 2003), part of the dorsoventral patterning defect of the telencephalon in the Sey/Sey embryos could be due to the abrogation of the Ngn2-dependent suppression of subpallial fate as discussed above. A recent genetic lineage tracing study has shown that the molecular ventralization of pallial progenitors in Pax6 mutants results in the respecification of the neuronal progeny of a subset of cortical glutamaterigic progenitors into a subpallial GABAergic interneuron phenotype (Kroll \& O'Leary, 2005). Thus, Pax6, like Ngn2, is required for the establishment of a correct neurotransmitter phenotype in pallial neurons (Schuurmans et al., 2004; Kroll \& O'Leary, 2005).

The graded expression of Pax 6 in cortical progenitors suggests that it may provide positional information for region-specific differentiation of the developing cortex. During corticogenesis, Pax6 is expressed at its highest level in progenitors of the ventral pallium, which appear to be defective in Pax6 mutants based on the absence of the markers sFrp2 and Dbx1, specific for this region (Kim et al., 2001; Yun et al., 2001; Assimacopoulos et al., 2003). At least one allele of either Pax6 or the nuclear orphan receptor Tlx is required for the expression of $s F r p 2$ in the neuroepithelium of the ventral pallium, suggesting a genetic interaction between these two genes in patterning of the lateral telencephalon (Stenman et al., 2003). The strong expression of Pax6 in ventral pallial progenitors is essential for the specification of the claustrum, the endopiriform nucleus and the piriform cortex (Stoykova et al., 2000) as well as the amygdalar lateral, basolateral and basomedial nuclei and the nucleus of the lateral olfactory tract, which all fail to form in the Small eye mutant (Tole et al., 2005).

\section{Pax6 and the specification of the cortical progenitors}

Cortical progenitors are heterogeneous. At the onset of the neurogenesis, Pax6 is expressed by the majority of radial glial cells that divide at the apical surface of the cortical VZ (Malatesta et al., 2000; Hartfuss et al., 2001; reviewed by Götz et al., 2002). The basal progenitors, located and dividing at some distance from the apical surface of the VZ (Haubensak et al., 2004), do not seem to express glial markers GLAST, hGFAP-Cre transgene and Pax6 (Malatesta et al., 2003), but the majority of them express instead Tbr2 and Ngn2 (Miyata et al., 2004; Englund et al., 2005).

Pax6 is an intrinsic molecular determinant of radial glial progenitors and, in the absence of Pax6, these cells present defects in their mitotic cycle, molecular phenotype and morphology (Götz et al., 1998). In the Small eye mutants the proliferation of cortical progenitors increases at early stages (Götz et al., 1998; Warren et al., 1999; Estivill-Torrus et al., 2002), suggesting that corticogenesis in Pax6 loss-of-function results from the residual neurogenic activity of basal progenitors only (Heins et al., 2002; Haubst et al., 2004). A number of approaches, including cell lineage analysis in dissociated and slice cultures (Malatesta et al., 2000; Miyata et al., 2001; Noctor et al., 2004) and fate-mapping studies in vivo (Malatesta et al., 2003; Anthony et al., 2004), have now demonstrated that radial glial cells act as pluripotent progenitors, generating both neuronal and glial cells. Interestingly, both loss- and gain-of-function experiments have shown that Pax6 endows radial glial progenitors with their neurogenic activity

FIG. 2. Model of cortical lamination. A pool of multipotent VZ progenitors could generate deep layer (DL) neurons, a process depending on the function of Ngn genes (Schuurmans et al., 2004). VZ progenitors also produce a secondary proliferative zone, the subventricular zone (SVZ). Evidence available so far indicates that the SVZ contains at least two subpopulations of cells: Satb2 ${ }^{+}$cells and Svet $1^{+}$cells. Both cell subtypes can be detected in the SVZ at the stage E13.5. Satb2 ${ }^{+}$cells start migrating out of the SVZ shortly after their initial detection. Svet $1^{+}$cells, in contrast, need to spend several days in the SVZ and start to migrate only after stage E17.5. Pax6 seems to be required for the differentiation of the Svet ${ }^{+}$cells, but not for the Satb2 ${ }^{+}$cells. Both cell subpopulations appear to express Cuxl and Cux2.

FIG. 3. Confocal microscopic images of layer 5 pyramidal neurons showing that the three neurofilament antibodies (red) specifically stained neurons which project subcortically, but they did not stain cells with projections to the contralateral cortex (all populations contain green microspheres). (A and B) SMI-32, (D and E) N200 and $(\mathrm{G}$ and $\mathrm{H})$ FNP-7 were specifically located in $(\mathrm{A}, \mathrm{D}$ and $\mathrm{G})$ the spinal cord and $(\mathrm{B}, \mathrm{E}$ and $\mathrm{H})$ superior colliculus projecting layer 5 neurons (arrows indicate examples of double labelling). (C, F and I) Contralateral cortex-projecting neurons (green microspheres indicated by arrowheads) did not express (C) SMI-32, (F) N200 or (I) FNP-7. The open arrowheads indicate neurons expressing the neurofilaments, but do not contain green microspheres and thus do not project to the contralateral cortex. Scale bar, $20 \mu \mathrm{m}$. (Reproduced with permission from Voelker et al., 2004). 
(Heins et al., 2002; Haubst et al., 2004). Analysis of the cortical phenotype of Pax6 mutants with defects restricted to either the pairedor the homeodomain indicated, furthermore, that the control of progenitor proliferation, neurogenesis and dorsoventral patterning is mediated mostly by the canonical Pax6 isoform which only depends on the function of the paired domain (Haubst et al., 2004).

One of the several enhancers of Ngn2 (E1-Ngn2) is only active in the part of the Pax6 expression domain (mostly in the ventral and lateral pallium all along the PSPB) that expresses Pax6 at its highest levels. The activity of this enhancer is directly regulated by Pax6 in a dosagedependent manner (Scardigli et al., 2003). Ngn2 expression in this region is lost in a Pax6-null mutant background (Stoykova et al., 2000; Schuurmans et al., 2004) while it becomes expanded when the dose of Pax6 is increased (Scardigli et al., 2003). Thus, the concentration level of patterning protein Pax 6 in cortical progenitors determines the expression pattern of proneural gene $\mathrm{Ngn} 2$, providing one of the first pieces of evidence in vertebrates of a direct regulatory link between neural patterning and neurogenesis (Scardigli et al., 2003).

\section{Pax6 in cortical layer formation}

The cortex is organized radially into six layers (each of which contains neurons with distinct morphologies, projection patterns and neurotransmitter phenotype) and tangentially into numerous functional domains (Mallamaci \& Stoykova, 2006). Postmitotic neurons of different layers are born in the proliferating progenitors cells in the VZ and SVZ in an inside-first, outside-last pattern (reviewed by McConnell, 1988). The time of birth of the neurons produced in the cortical germinal zones at sequential developmental stages is tightly linked with their laminar identity: early progenitors (in mouse between embryonic stages E10 and E14) generate the neurons of the lower layer 6 and layer 5, while progenitors after stage E14.5 produce exclusively neurons for the upper supragranular cortical layers 4, 3 and 2 (McConnell, 1988). Data from transplantation experiments indicated that during development the fate potential of the neuronal progenitors in the VZ is progressively restricted and by the end of the corticogenesis the progenitors are lineally committed to producing upper layer neurons (Frantz \& McConnell, 1996; Desai \& McConnell, 2000).

As discussed in the preceding paragraphs, elimination of $\mathrm{Ngnl}$ and -2 function appears to affect mostly the specification of neurons born early in corticogenesis which will migrate into the lower cortical layers (Schuurmans et al., 2004). In contrast, accumulating recent evidence indicate that the neurogenic factor Pax6 is required predominantly for the specification of neurons born in the later part of corticogenesis, which migrate into the upper cortical layers. Previous data from morphological (Schmahl et al., 1993) and bromodeoxyuridine-labelling studies in embryos of the mouse (Caric et al., 1997) and the rat Small eye mutants (Fukuda et al., 2000) suggested that the supragranular cortical neurons are specifically affected in the mutant $\mathrm{CP}$, possibly due to non-cell-autonomous migration defects of late-born neurons (Caric et al., 1997) or defective radial glial processes, hampering the normal migration of neurons to their target locations in the CP (Götz et al., 1998). Expression analyses using molecular markers for distinct layers have also suggested that in the Sey/Sey cortex the upper cortical layers are malformed while the lower layers are generally not affected (Nieto et al., 2004; Tarabykin et al., 2001; Schuurmans et al., 2004; Zimmer et al., 2004). Thus, the generation of neurons of the lower and upper cortical layers appear to be a specific output of Ngn1-Ngn2- and Pax6-controlled genetic pathways, respectively (Schuurmans et al., 2004).
Results from several studies suggest that the SVZ may specifically contribute to the generation of the upper corical layers in primates (Sidman \& Rakic, 1973; Smart et al., 2002) as well as in mice (Smart \& McSherry, 1982; Smart \& Smart, 1982; Tarabykin et al., 2001). By using cell cycle-specific markers in birthdating experiments, Lukaszewicz et al. (2005) recently convincingly demonstrated that indeed the progenitors of the SVZ in primates produce the supragranular layer neurons. The role of molecular cues in the SVZ for changing the temporal identity of cortical progenitors from early progenitors (producing lower cortical layers) to late progenitors (producing upper cortical layers) has only recently begun to be understood. Genes with a transient or specific expression in the cortical VZ and SVZ and in distinct cortical layers would be appropriate candidates for exerting control functions for specification of the temporal identity of cortical progenitors. Several recent studies support the idea that Pax6 might have an essential role in this process. The recently identified cDNA sequence subventricular tag (Svet1) shows an intriguing expression pattern confined to both SVZ progenitors and upper cortical layers at a perinatal stage (Tarabykin et al., 2001). In the homozygous Sey/Sey embryos the expression of the POU homeodomain gene Otxl, which is normally restricted to the $\mathrm{VZ}$ and the deep cortical layers (Frantz et al., 1994), is not altered (Stoykova et al., 2000; Tarabykin et al., 2001). However, the expression of Svet1 in the abnormal SVZ and CP of Sey/Sey cortex is abolished, suggesting that Pax6 is involved in the determination of the upper cortical layer identity in the SVZ (Tarabykin et al., 2001; see Fig. 2). In the developing cortex, Cux1 and Cux2, two homologues of Drosophila Cut, are specifically expressed in the VZ and in mitotically active cells of the SVZ, respectively, whereas later on their expression is confined to distinct subpopulations of the upper cortical layers (Nieto et al., 2004; Zimmer et al., 2004). Interestingly, the expression of Cux2 in the SVZ and the expression of both Cux2 and Cuxl in the supragranular cortical layers is severely diminished in the Pax6-mutant cortex, suggesting that in addition to Svet 1 these two genes might also act as determinants for the specification of the upper cortical layer neurons in a Pax6-dependent pathway (Nieto et al., 2004; Zimmer et al., 2004).

It is unclear whether the expression of Svet 1 and Cux2 is an intrinsic property of distinct cell subpopulations of the SVZ or whether their expression is induced by environmental cues which are available within the SVZ at late developmental stages. Interestingly, GABAergic interneurons which normally migrate from the subpallium into the SVZ of the pallium might play a role in providing such environmental signals. As recently shown, GABA can dramatically increase the proliferation of $\mathrm{VZ}$ progenitors whereas the proliferation of the SVZ is substantially inhibited (Haydar et al., 2000).

In addition to Pax6, the nuclear orphan receptor Tlx also appears to be involved in the generation of upper cortical layers (Land \& Monaghan, 2003a,b). Loss of function of both Pax6 and Tlx1 genes results in increased severity of the defects in the dorsoventral telencephalic patterning (Stenman et al., 2003) and in specification generation of the upper cortical layers in the rostrolateral cortex, implying a genetic cooperation between these two factors (Schuurmans et al., 2004).

\section{Molecular determinants of cortical layer formation}

The great cellular heterogeneity of the cerebral cortex renders difficult the classification of cortical neuron subtypes solely on the basis of their developmental birthday and morphological and physiological characteristics. A number of specific molecular markers for neurons of distinct cortical layers have been recently identified (see Table 1) and 
these have a profound impact on the elaboration of a more comprehensive classification of the cortical neurons.

Many of these genes are not expressed uniformly within a given layer. Their expression borders often demarcate boundaries between different cortical areas within a certain layer or have rostrocaudal or mediolateral gradients of expression. For instance, Cadherin-6 (Suzuki et al., 1997) and ephrin-A5 (Mackarehtschian et al., 1999) are predominantly expressed in the parietal cortex, while the expressions of Lmo4 and Climla (Bulchand et al., 2003) are predominantly confined to the upper layers of the frontal and occipital cortex, respectively. Some genes with layer-restricted expression have been mutated and shown to play an essential role in normal corticogenesis. Mutation of the T-box transcription factor Tbrl causes a specific defect of the generation of the layer 6 neurons as well as Cajal-Retzius cells of the marginal zone and subplate neurons, while the production of upper cortical layers is not affected (Hevner et al., 2001). Consistent with its restricted expression in layer 6 and layer 5 , the homeobox transcription factor Otx1 is required for the normal connectivity of layer 5 neurons (Weimann et al., 1999). Two other genes with restricted expression in the supragranular cortical layers which encode the POU-domain transcription factors Brn1 and Brn2 were found to have essential roles for normal production and migration of layers 2-4 neurons (McEvilly et al., 2002; Sugitani et al., 2002).

Given the importance of molecular markers in defining layerspecific neuronal subtypes (Hevner et al., 2003), efforts have recently been made to identify novel genes with laminar-restricted expression in the cortex. In one set of experiments, cDNA subtraction between mRNA pools isolated from different stages of cortical development

TABLE 1. Summary of some layer-specific genetic markers

\begin{tabular}{|c|c|c|c|c|c|c|}
\hline \multirow[b]{2}{*}{ Gene Gene } & \multicolumn{6}{|c|}{ Layer } \\
\hline & 1 & $2 / 3$ & 4 & 5 & 6 & $6 \mathrm{~b}$ \\
\hline$b H L H b 5^{\mathrm{d}}$ & & + & + & & & \\
\hline $\operatorname{Brn} 2^{\mathrm{c}}$ & & + & & & & \\
\hline Clim 1a ${ }^{\mathrm{b}}$ & & & & + & & \\
\hline$C T I P 2^{\mathrm{h}}$ & & & & + & & \\
\hline Cux $2^{\overline{\mathrm{d}}, \mathrm{e}}$ & & + & + & & & \\
\hline Deltex-like $e^{\mathrm{g}}$ & & + & + & & & \\
\hline$E r 81^{\mathrm{c}}$ & & & & + & & \\
\hline$F_{0 x O 1^{\mathrm{d}}}$ & & + & & & & \\
\hline$K_{l f} \sigma^{\mathrm{d}}$ & & & + & & & \\
\hline Koral & & & & + & & \\
\hline Latexin $^{\mathrm{i}}$ & & & & & + & \\
\hline $\operatorname{Lmo}^{\mathrm{b}}$ & & + & + & & + & \\
\hline$L m o 4^{\mathrm{b}, \mathrm{d}}$ & & + & + & & + & \\
\hline$M E F-2 C^{\mathrm{d}, \mathrm{g}}$ & & + & + & & & \\
\hline$N R 4 A 3^{\mathrm{d}}$ & & & & + & + & \\
\hline $\operatorname{Otx} I^{\mathrm{c}}$ & & & & + & + & \\
\hline Reelin $^{\mathrm{c}}$ & + & & & & & \\
\hline$R O R-b^{\mathrm{c}}$ & & & + & & & \\
\hline Satb1 $1^{\text {a }}$ & + & & & + & + & + \\
\hline Satb2 ${ }^{\mathrm{a}}$ & & + & + & & & \\
\hline$S C F^{\mathrm{g}}$ & & + & + & & & \\
\hline$S C I P^{\mathrm{c}}$ & & + & & & + & \\
\hline Sox $5^{\mathrm{d}}$ & & & & + & + & \\
\hline Svet $1^{\mathrm{f}}$ & & + & + & & & \\
\hline$T b r 1^{\mathrm{c}}$ & + & & & & + & + \\
\hline Unc $5 h 4^{\mathrm{g}}$ & & & + & & & \\
\hline Zfp $312^{\mathrm{g}}$ & & & & + & + & \\
\hline
\end{tabular}

${ }^{\mathrm{a} B r i t a n o v a}$ et al. (2005); ${ }^{\mathrm{b}} \mathrm{Bulchand}$ et al. (2003); ${ }^{\mathrm{c}} \mathrm{Hevner}$ et al. (2003); ${ }^{\mathrm{d}}$ Gray et al. (2004); ${ }^{\mathrm{e}}$ Nieto et al. (2004) and Zimmer et al. (2004); ${ }^{\mathrm{f}}$ Tarabykin et al. (2001); ${ }^{\mathrm{g}}$ Zhong et al. (2004); ${ }^{\mathrm{h}}$ Arlotta et al. (2005); ${ }^{\mathrm{i}}$ Arimatsu et al. (1999). was performed and resulted in isolation of several novel genes with expression restricted to distinct cortical layers (Tarabykin et al., 2001; Britanova et al., 2005). One of these genes, Svet1, is a marker of proliferating cells in the SVZ and some cells in the upper cortical layers, as mentioned above. Two other genes, Satb1 and Satb2, members of a novel family of transcription factors, are expressed in a mutually exclusive manner in the developing cortex. Satbl expression is detected in cells of the marginal zone (layer 1) and in the deep layers, overlapping with Tbrl expression, while most Satb2-positive cells are located within layers 2-4. Although a great number of supragranular neurons express Satb2, it seems that Satb2 is not a universal marker of the upper cortical layer neurons. Thus, most of the cells that express Tbr1 at a high level do not coexpress Satb2, and Satb2-positive upper cortical neurons do not coexpress Svet1 (Britanova et al., 2005). Neurons born in the SVZ stay several days in this region ('sojourn phase') before they migrate out towards their final location in the CP (Bayer \& Altman, 1991). In contrast to Svet1positive cells which stay several days in the SVZ and appear to require Pax6 function for their differentiation, Satb2-positive upper cortical layer neurons do not seem to stay in the SVZ, or to be affected in the Small eye mutant (O. Britanova, P. Gruss and V. Tarabykin, unpublished observations). It is still not clear whether Satb2 ${ }^{+}$neurons are derived from Cux2-expressing cells in the SVZ or whether these are two independent cell subpopulations. Altogether, current evidence suggests that two subtypes of upper cortical layer neurons might coexist whose generation might be, respectively, dependent and independent of Pax6 function.

Koral is another newly identified gene which encodes a protein of 378 amino acids (NM_177869) of still unknown function (V. Tarabykin and P. Gruss, unpublished observations). In the mouse developing cortex, Koral expression is detected from E15.5 onwards in a subpopulation of layer 5 neurons within the upper part of the Otx 1 expression domain, while its expression is downregulated after birth and in adult brain. The expression of the gene Clstn 2 is first detected in migrating neurons of the intermediate zone of the cortex and later on in young neurons of layers 2-4 (O. Britanova, P. Gruss and V. Tarabykin, unpublished observation).

By using a similar cDNA subtraction approach, Zhong et al. (2004) have identified Unc5h4 as a gene expressed mostly in layer 4 neurons. Interestingly, Svet 1 transcript, which does not seem to encode any protein, is transcribed from an intron of the Unc5h4 gene, and both genes have a highly similar expression patterns (V. Beilinson and V. Tarabykin, unpublished observation), suggesting that the same enhancer might control their expression. Three other genes, deltex-like gene, stem cell factor $(S C F)$ and myocyte-specific enhancer factor-2C $(M E F-2 C)$ have also been identified in this study as novel markers with a restricted expression in layers $2-4$.

Recently, a genome-scale expression analysis of genes encoding all putative transcription factors revealed layer-restricted expression pattern for some of them (Gray et al., 2004). The transcription factors FoxO1, NR4A2 (Nurr1), bHLHb5 and Lmo4 are expressed in cells of the upper layers, while the expression of Sox5, Klf6, Zfp312 and $N R 4 A 3$ is confined to cells of the deep layers (see Table 1). Apart from their layer-specific expression, some of the genes are expressed in a region-specific manner or form gradients. For instance, NR4A3 is expressed with a prominent medial (high) to lateral (low) gradient, while $M e f 2 C$ is more abundantly expressed in the lateral than in the medial cortex (Gray et al., 2004).

Finally, a recent microarray analysis of the transcription profile of callosal and corticospinal cortical projection neurons has revealed novel marker genes for these neuronal subpopulations (Arlotta et al., 2005; see below). Fourteen genes identified in this study showed 
expression confined to morphologically distinct subpopulations of corticospinal neurons, which might potentially be instructive concerning the generation and/or differentiation of corticospinal motor neuron subtypes.

\section{Specification of the layer 5 pyramidal neuronal subtypes}

The cortical projection neurons are further classified by their morphology, electrophysiology, hodology and neurochemical characteristics in relation to the laminar position of the cell body (Peters \& Jones, 1985). In this part of the review we shall describe recent studies on subtypes identification of layer 5 pyramidal neurons in the rodent cerebral cortex, as they provide an exceptional model system to study cortical neuronal specification within the same cortical lamina.

\section{Two major classes of layer 5 pyramidal cells; an accessible model for the study of target selection and dendritic and physiological differentiation}

Pyramidal cells of layer 5 of the adult rodent cortex fall into two major classes which can be distinguished on the basis of their projection site, morphology and physiological properties in the adult (Klein et al., 1986; Hallman et al., 1990; Larkman \& Mason, 1990). Pyramidal neurons of layer 5 in the rat are born between E15 and E18, migrate to layer 5 by E19-20 (Miller, 1998) and appear indistinguishable when they first migrate into their final position in the $\mathrm{CP}$, all having stout apical dendrites reaching layer 1 with terminal tufts, and none of them fire bursts after the injection of depolarizing currents. However, there seems to be a sequential expression of characteristics (see Table 2). Shortly after they have migrated into the $\mathrm{CP}$, the pyramidal neurons grow correctly at E19 to postnatal day (P)0 towards the appropriate target: type I neurons reach superior colliculus, basal pons or spinal cord, while type II neurons reach the contralateral hemisphere. However, both type of pyramidal neurons do not invade the target regions until the early postnatal period ( $\mathrm{P} 0-3)$, and morphologies of the two types do not begin to diverge until $\approx$ P5 (Koester \& O'Leary, 1992, 1993). Type I cells with axons to the superior colliculus maintain their thick tufted apical dendrites, and begin to fire bursts

TABLE 2. Time frames of the sequential differentiation of the two major classes of pyramidal neurons in the rat cortex

\begin{tabular}{llll}
\hline Feature & Age & Type I & Type II \\
\hline $\begin{array}{l}\text { Cell birth } \\
\text { Innervation of target }\end{array}$ & $\begin{array}{l}\text { E15-16 } \\
\text { E21-P0 }\end{array}$ & Spinal cord & $\begin{array}{c}\text { Contralateral } \\
\text { cortex } \\
\text { Striatum }\end{array}$ \\
$\begin{array}{l}\text { Somatodendritic } \\
\text { morphology }\end{array}$ & P5-7 & $\begin{array}{l}\text { Superior colliculus } \\
\text { Tufted }\end{array}$ & Non-tufted \\
Firing properties & P15-21 & Bursting & Non-bursting \\
\hline
\end{tabular}

Both types of pyramidal neurons are born in rat at E15-16. By E19-P0 both set reach their appropriate target: type I neurons reach superior colliculus, basal pons or spinal cord while type II neurons reach the contralateral hemisphere and, shortly afterwards (P0-P3), invade their target regions. By P5 the morphologies of the two types start to diverge. Type I cells with axons to the superior colliculus maintain their thick tufted apical dendrites while type II cells with axons to the contralateral hemisphere transform to cells with slender apical dendrites without terminal tufts. Type I neurons start to fire bursts of action potentials from the end of the second postnatal week, whereas Type II cells never fire bursts. The data for the Table have been collected from Koester \& O'Leary (1992), Kasper et al. (1994) and Larkman \& Mason (1990). after the second postnatal week (Kasper et al., 1994). Type 2 cells with axons to the contralateral hemisphere transform to cells with slender apical dendrites with fewer oblique branches that end without terminal tufts, usually in the upper part of layers $2 / 3$, and never fire bursts (Kasper et al., 1994). Larkman \& Mason (1990) also showed that, in adult rat visual cortex, these two groups differ in other intrinsic physiological properties, such as input resistance and time constant. Interestingly, recent studies have revealed that the electrophysiological differences emerge earlier than previously believed (Christophe et al., 2005). Deisz (1988) proposed that a calcium-activated potassium current controls the generation of a depolarizing $\mathrm{Ca}^{2+} / \mathrm{Na}^{+}$envelope underlying the bursts in neurons, but the factors controlling its development are not known (Schwindt \& Crill, 1997). While most experiments were performed in rat visual and somatosensory cortices, the existence of two similar types of layer 5 neurons in other cortical regions (Games \& Winter, 1988; Chagnac-Amitai et al., 1990) suggests that it is a general feature of rodent neocortex.

The emergence of the differences between these two distinct cell classes provides an excellent model system for studying the contribution of genetic and epigenetic factors during cortical development and provide numerous technical advantages. Layer 5 pyramidal cells are among the largest cells in the cerebral cortex; this is of considerable advantage for recording and single-cell RT-PCR studies (Christophe et al., 2005). The subclasses reach their specific targets before any distinctions can be observed in their morphology or physiology so it is relatively easy to label them selectively in living or fixed tissue through their specific projections and before their full differentiation with fluorescent latex beads or carbocyanine dyes (Koester \& O'Leary, 1992; Kasper et al., 1994). This permits the selective identification of the different cells in combination with immunohistochemistry, in situ hybridization or single-cell recording (Hevner et al., 2003; Voelker et al., 2004; Arlotta et al., 2005; Christophe et al., 2005). In spite of these advantages of this system, it seems that our current knowledge of interneuron populations is much better (Cauli et al., 1997; Markram, 2004) than that of pyramidal cells. The paucity of specific markers for classes and subclasses of pyramidal neurons not only holds back our efforts to understand development but also hinders our studies of functional cortical circuits.

\section{Molecular characterization of the layer 5 pyramidal cells}

Previous and recent studies have isolated molecules which serve as molecular markers for layer 5 neurons: Otx1, a transcription factor expressed in layers 5/6, which is specific to type I neurons (Frantz et al., 1994; Weimann et al., 1999); SMI-32, N200 and FNP-7, which are neurofilaments only expressed in type I neurons (Hornung \& Riederer, 1999; Voelker et al., 2004; see Fig. 3); ER81, an ETS transcription factor expressed in both neuronal cell types (Hevner et al., 2003; Yoneshima et al., 2006); Lmo4, a LIM domain-containing protein known to be expressed in layers 2/3 and 5 (Bulchand et al., 2003), which is a specific marker for type II neurons (Arlotta et al., 2005); and CTIP2, Fez6 genes specifically expressed in layer 5 type I neurons (Arlotta et al., 2005; Molyneaux et al., 2005).

Co-localization studies with Otx1 and ER81 suggested that the two markers are not expressed within the same postnatal layer 5 neurons; moreover, ER81 is also expressed in some type II layer 5 pyramidal neurons (Hevner et al., 2003; Yoneshima et al., 2006). Although ER81 and N200 have been shown to label type I projection neurons in layer 5, retrograde labelling and immunohistochemistry for the two markers revealed that they are never coexpressed in the same projection neurons, suggesting that there are at least two distinct neurochemical subpop- 
ulations within type I layer 5 pyramidal cells (Rolph et al., 2005; A. Cheung, C. Voelker, R. Rolph and Z. Molnar, unpublished observations; see also Fig. 3). An important aim of these studies is to be able to unify molecular classification with other aspects of layer 5 neuronal classification in the adult and during development (Molnár \& Cheung, 2006). As pointed out above, potential molecular markers for layer 5 neurons are continually being found and the correlation of these markers with other aspects of neuronal phenotype will result not only in a more comprehensive classification of layer 5 projection neurons but also in the better understanding of the genetic and epigenetic programs of differentiation.

Layer 5 neurons have, furthermore, been shown to be divided into five major classes based upon multidimensional cluster analysis of a series of dendritic morphological variables, revealed by biocytin staining, in mouse primary visual cortex (Tsiola et al., 2003). Using electrophysiological recording of prelabelled neurons from their specific projection sites, combined with morphological reconstruction and immunocytochemistry and with single-cell gene expression profiles for various markers (Audinat et al., 1996; Christophe et al., 2005; Sugino et al., 2006), will further advance our understanding into the differences (or similarities) between the two neurochemically distinct populations. By performing these studies at specific periods of differentiation (Arlotta et al., 2005; Christophe et al., 2005), we hope to get an insight into the mechanisms controlling the developmental decision making.

\section{Conclusions}

This is an exciting time for researchers involved in the study of cortical development, as rapid progress is made in identifying molecules playing key roles in the specification and differentiation of cortical neurons, and long-standing issues, such as the degree of heterogeneity of cortical progenitors and the lineal relationships of different progenitor subpopulations, are finally being addressed. This review has focused exclusively on intrinsic regulators of cortical neurogenesis, reflecting the interests and biases of the authors. However, throughout neurogenesis, cortical progenitors and neurons are influenced by extrinsic signals. An important challenge ahead is to acquire a more comprehensive understanding of the regulation of cortical development, including both intrinsic and extrinsic determinants, and to identify the mechanisms by which the signalling pathways and transcription factors involved interact.

\section{Acknowledgements}

Work carried out in both laboratories (Z.M.; A.S. and V.T.) was supported by the European Community 'Concorde' grant QLG3-2000-00158. The F.G. laboratory is supported by the Medical Research Council (UK). Work in Z.M.'s lab was supported by Grants from the Medical Research Council (GO3000200), the Welcome Trust (063974/B/01/Z, the Human Frontier Science Program (RGP0107/2001) and St John's College, Oxford. Work in A.S.'s lab was supported by the Max-Plack-Gessellschaft.

\section{Abbreviations}

bHLH, basic helix-loop-helix; CP, cortical plate; E, embryonic day; Ngn1, Neurogenin1; Ngn2, Neurogenin2; P, postnatal day; Sey/Sey, homozygous Small eye; Svet1, subventricular tag1; SVZ, subventricular zone; VZ, ventricular zone.

\section{References}

Anthony, T.E., Klein, C., Fishell, G. \& Heinz, N. (2004) Radial glia serve as neuronal progenitors in all regions of the central nervous system. Neuron, 41, 881-890.
Arimatsu, Y., Ishida, M., Sato, M. \& Kojima, M. (1999) Corticocortical associative neurons expressing Latexin: Specific cortical connectivity formed in vivo and in vitro. Cereb. Cortex., 9, 565-576.

Arlotta, P., Molyneaux, B.J., Chen, J., Inoue, J., Kominami, R. \& Macklis, J.D. (2005) Neuronal subtype-specific genes that control corticospinal motor neuron development in vivo. Neuron, 45, 207-221.

Assimacopoulos, S., Grove, E. \& Ragsdale, C.W. (2003) Identification of a Pax6-dependent epidermal growth factor family signaling source at the lateral edge of the embryonic cerebral cortex. J. Neurosci., 23, 6399-6403.

Audinat, E., Lambolez, B. \& Rossier, J. (1996) Functional and molecular analysis of glutamate-gated channels by patch-clamp and RT-PCR at the single cell level. Neurochem. Int., 28, 119-136.

Bayer, S.A. \& Altman, J. (1991) Neocortical Development, 1st edn. Raven Press, New York.

Bertrand, N., Castro, D.S. \& Guillemot, F. (2002) Proneural genes and the specification of neural cell types. Nat. Rev. Neurosci., 3, 517-530.

Bopp, D., Burry, M., Baumgartner, S., Frigerio, G. \& Noll, M. (1986) Conservation of a large protein domain in the segmentation gene paired and in functionally related genes of Drosophila. Cell, 47, 1033-1040.

Britanova, O., Akopov, S., Lukyanov, S., Gruss, P. \& Tarabykin, V. (2005) Novel transcription factor Satb2 interacts with matrix attachment region DNA elements in tissue-specific manner and demonstrates cell-typedependent expression in the developing mouse CNS. Eur. J. Neurosci., 21, 658-668.

Brunet, J.F. \& Ghysen, A. (1999) Deconstructing cell determination: proneural genes and neuronal identity. Bioessays, 21, 313-328.

Bulchand, S., Subramanian, L. \& Tole, S. (2003) Dynamic spatiotemporal expression of LIM genes and cofactors in the embryonic and postnatal cerebral cortex. Dev. Dyn., 226, 460-469.

Caric, D., Gooday, D., Hill, R.E., McConnell, S.K. \& Price, D.J. (1997) Determination of the migratory capacity of embryonic cortical cells lacking the transcription factor Pax-6. Development, 124, 5087-5096.

Cauli, B., Audinat, E., Lambolez, B., Angulo, M.-C., Ropert, N., Tsuzuki, K., Hestrin, S. \& Rossier, J. (1997) Molecular and physiological diversity of cortical nonpyramidal cells. J. Neurosci., 17, 3894-3906.

Caviness, V.S. Jr, Goto, T., Tarui, T., Takahashi, T., Bhide, P.G. \& Nowakowski, R.S. (2003) Cell output, cell cycle duration and neuronal specification: a model of integrated mechanisms of the neocortical proliferative process. Cereb. Cortex, 13, 592-608.

Chagnac-Amitai, Y., Luhmann, H.J. \& Prince, D.A. (1990) Burst generating and regular spiking layer 5 pyramidal neurons of rat neocortex have different morphological features. J. Comp. Neurol., 296, 598-613.

Chapouton, P., Gartner, A. \& Götz, M. (1999) The role of Pax6 in restricting cell migration between developing cortex and basal ganglia. Development, 126, 5149-5579.

Christophe, E., Doerflinger, N., Lavery, D., Charpak, S., Molnár, Z. \& Audinat, E. (2005) Two populations of layer V pyramidal cells of the mouse neocortex: Development and sensitivity to anesthetics. J. Neurophysiol., 94, 3357-3367.

Czerny, T., Schaffner, G. \& Busslinger, M. (1993) DNA sequence recognition by Pax proteins: bipartite structure of the paired domain and its binding site. Genes Dev., 7, 2048-2061.

Davis, A.A. \& Temple, S. (1994) A self-renewing multipotential stem cell in embryonic rat cerebral cortex. Nature, 372, 263-266.

Deisz, R. (1988) The current components of intrinsic bursting neurones of the guinea pig neocortex. Plugers Arch., 411 (Suppl. R.), 126.

Desai, A.R. \& McConnell, S.K. (2000) Progressive restriction in fate potential by neuronal progenitors during cerebral cortical development. Development, 127, 2863-2872.

Edlund, T. \& Jessell, T.M. (1999) Progression from extrinsic to intrinsic signaling in cell fate specification: a view from the nervous system. Cell, 96, 211-224.

Englund, C., Fink, A., Lau, C., Pham, D., Daza, R.A., Bulfone, A., Kowalczyk, T. \& Hevner, R.F. (2005) Pax6, Tbr2, and Tbr1 are expressed sequentially by radial glia, intermediate progenitor cells, and postmitotic neurons in developing neocortex. J. Neurosci., 25, 247-251.

Epstein, J.A., Glaser, T., Cai, J., Jepeal, L., Walton, D.S. \& Maas, R.L. (1994) Two independent and interactive DNA-binding subdomains of the Pax6 paired domain are regulated by alternative splicing. Genes Dev., 8, 2022-2034.

Estivill-Torrus, G., Pearson, H., van Heyningen, V., Price, D.J. \& Rashbass, P. (2002) Pax6 is required to regulate the cell cycle and the rate of progression from symmetrical to asymmetrical division in mammalian cortical progenitors. Development, 129, 455-466.

Fan, G., Martinowich, K., Chin, M.H., He, F., Fouse, S.D., Hutnick, L., Hattori, D., Ge, W., Shen, Y., Ten Wu, H.H.J., Shuai, K. \& Sun, Y.E. (2005) DNA methylation controls the timing of astrogliogenesis through regulation of JAK-STAT signaling. Development, 132, 3345-3356. 
Farah, M.H., Olson, J.M., Sucic, H.B., Hume, R.I., Tapscott, S.J. \& Turner, D.L. (2000) Generation of neurons by transient expression of neural bHLH proteins in mammalian cells. Development, 127, 693-702.

Fode, C., Ma, Q., Casarosa, S., Ang, S.L., Anderson, D.J. \& Guillemot, F. (2000) A role for neural determination genes in specifying the dorsoventral identity of telencephalic neurons. Genes Dev., 14, 67-80.

Frantz, G.D., Bohner, A.P., Akers, R.M. \& McConnell, S.K. (1994) Regulation of the POU domain gene SCIP during cerebral cortical development. J. Neurosci., 14, 472-485.

Frantz, G.D. \& McConnell, S. (1996) Restriction of the late cerebral cortical progenitors to an upper-layer fate. Neuron, 17, 55-61.

Fukuda, T., Kawano, H., Osumi, N., Eto, K. \& Kawamura, K. (2000) Hisogenesis of the cerebral cortex in rat fetuses with a mutation in the Pax-6 gene. Brain Res. Dev. Brain Res., 120, 65-75.

Games, K.D. \& Winter, J.A. (1988) Layer V in rat auditory cortex: Projections to inferior colliculus and contralateral cortex. Hear Res., 34, 1-25.

Gorski, J.A., Talley, T., Qiu, M., Puelles, L., Rubenstein, J.L. \& Jones, K.R. (2002) Cortical excitatory neurons and glia, but not GABAergic neurons, are produced in the Emx1-expressing lineage. J. Neurosci., 22, 6309-6314.

Götz, M., Hartfuss, E. \& Malatesta, P. (2002) Radial glial cells as neuronal precursors: a new perspective on the correlation of morphology and lineage restriction in the developing cerebral cortex of mice. Brain Res. Bull., 57, 777-788.

Götz, M., Stoykova, A. \& Gruss, P. (1998) Pax6 controls differentiation in the cerebral cortex. Neuron, 21, 1031-1044.

Gray, P.A., Fu, H., Luo, P. \& Zhao, Q., YuJ., Ferrari, A., Tenzen, T., Yuk, D.I., Tsung, E.F., Cai, Z., Alberta, J.A., Cheng, L.P., Liu, Y., Stenman, J.M., Valerius, M.T., Billings, N., Kim, H.A., Greenberg, M.E., McMahon, A.P., Rowitch, D.H., Stiles, C.D. \& Ma, Q. (2004) Mouse brain organization revealed through direct genome-scale TF expression analysis. Science, $\mathbf{3 0 6}$, 2255-2257.

Halevy, O., Novitch, B.G., Spicer, D.B., Skapek, S.X., Rhee, J., Hannon, G.J., Beach, D. \& Lassar, A.B. (1995) Correlation of terminal cell cycle arrest of skeletal muscle with induction of p21 by MyoD. Science, 267, 10181021.

Hallman, L.E., Schofield, B.R. \& Lin, C.S. (1990) Dendritic morphology and axon collaterals of corticotectal, cortico-pontine, and callosal neurons in layer V of the primary visual cortex of the hooded rat. J. Comp. Neurol., 272, $149-160$.

Hand, R., Bortone, D., Mattar, P., Nguyen, L., Heng, J.I., Guerrier, S., Boutt, E., Peters, E., Barnes, A.P., Parras, C., Schuurmans, C., Guillemot, F. \& Polleux, F. (2005) Phosphorylation of neurogenin2 specifies the migration properties and the dendritic morphology of pyramidal neurons in the neocortex. Neuron, 48, 45-62.

Hartfuss, E., Galli, R., Heis, N. \& Götz, M. (2001) Characterization precursor subtypes and radial glia. Dev. Biol., 229, 15-30.

Hatakeyama, J. \& Kageyama, R. (2004) Retinal cell fate determination and bHLH factors. Semin. Cell Dev. Biol., 15, 83-89.

Haubensak, W., Attardo, A., Denk, W. \& Huttner, W.B. (2004) Neurons arise in the basal neuroepithelium of the early mammalian telencephalon: a major site of neurogenesis. PNAS, 101, 3196-3201.

Haubst, N., Berger, J., Radjendirane, V., Graw, J., Favor, J., Saunders, G.F., Stoykova, A. \& Götz, M. (2004) Molecular dissection of Pax6 function: the specific roles of the paired domain and homeodomain in brain development. Development, 131, 6131-6140.

Haydar, T.F., Wang, F., Schwartz, M.L. \& Rakic, P. (2000) Differential modulation of proliferation in the neocortical ventricular and subventricular zones. J. Neurosci., 20, 5764-5774.

He, F., Ge, W., Martinowich, K., Becker-Catania, S., Coskun, V., Zhu, W., Wu, H., Castro, D., Guillemot, F., Fan, G., deVellis, J. \& Sun, Y.E. (2005) A positive autoregulatory loop of Jak-STAT signaling controls the onset of astrogliogenesis. Nat. Neurosci., 8, 616-625.

He, W., Ingraham, C., Rising, L., Goderie, S. \& Temple, S. (2001) Multipotent stem cells from the mouse basal forebrain contribute GABAergic neurons and oligodendrocytes to the cerebral cortex during embryogenesis. J. Neurosci., 21, 8854-8862.

Heins, N., Malatesta, P., Cecconi, F., Nakafuku, M., Tucker, K.L., Hack, M.A., Chapouton, P., Barde, Y.A. \& Götz, M. (2002) Glial cells generate neurons: the role of the transcription factor Pax6. Nat. Neurosci., 5, 308-315.

Hevner, R.F., Daza, R.A., Rubenstein, J.L., Stunnenberg, H., Olavarria, J.F. \& Englund, C. (2003) Beyond laminar fate: toward a molecular classification of cortical projection/pyramidal neurons. Dev. Neurosci., 25, 139-151.

Hevner, R.F., Shi, L., Justice, N., Hsueh, Y., Sheng, M., Smiga, S., Bulfone, A., Goffinet, A.M., Campagnoni, A.T. \& Rubenstein, J.L. (2001) Tbr1 regulates differentiation of the preplate and layer 6. Neuron, 29, 353-366.
Hill, R.E., Favor, J., Hogan, B.L., Ton, C.C., Saunders, G.F., Hanson, I.M., Prosser, J., Jordan, T., Hastie, N.D. \& van Heyningen, V. (1991) Mouse small eye results from mutations in a paired-like homeobox-containing gene. Nature, 354, 522-527.

Hornung, J.P. \& Riederer, B.M. (1999) Medium-sized neurofilament protein related to maturation of a subset of cortical neurons. J. Comp. Neurol., 414, $348-360$.

Ivanova, A., Nakahira, E., Kagawa, T., Oba, A., Wada, T., Takebayashi, H., Spassky, N., Levine, J., Zalc, B. \& Ikenaka, K. (2003) Evidence for a second wave of oligodendrogenesis in the postnatal cerebral cortex of the mouse. J. Neurosci. Res., 73, 581-592.

Kasper, E.M., Larkman, A.U., Lübke, J. \& Blakemore, C. (1994) Pyramidal neurons in layer 5 of the rat visual cortex. III. Differential maturation of axon targeting, dendritic morphology and electrophysiological properties. J. Comp. Neurol., 339, 495-518.

Kim, A.S., Anderson, S.A., Rubenstein, J.L., Lowenstein, D.H. \& Pleasure, S.J. (2001) Pax6 regulates expression of SFRP-2 and Wnt-7b in the developing CNS. J. Neurosci., 21, Rc132, 8 (1-5).

Klein, B.G., Mooney, R.D., Fish, S.E. \& Rhoades, R.W. (1986) The structural and functional characteristics of striate cortical neurons that innervate the superior colliculus and the lateral posterior nucleus in hamster. Neuroscience, 17, 57-78.

Koester, S.E. \& O’Leary, D.D. (1992) Functional classes of cortical projection neurons develop dendritic distinctions by class-specific sculpting of an early common pattern. J. Neurosci., 12, 1382-1393.

Koester, S.E. \& O’Leary, D.D. (1993) Connectional distinction between callosal and subcortically projecting cortical neurons is determined prior to axon extension. Dev. Biol., 160, 1-14.

Kroll, T.T. \& O'Leary, D.D. (2005) Ventralized dorsal telencephalic progenitors in. Pax6 mutant mice generate GABA interneurons of a lateral ganglionic eminence fate. Proc. Natl. Acad. Sci. USA, 102, 7374-7379.

Land, P.K. \& Monaghan, A.P. (2003a) Abnormal development of zinkcontaining cortical circuits in the absence of the transcription factor Tailess. Brain Res. Dev. Brain Res., 158, 97-101.

Land, P.K. \& Monaghan, A.P. (2003b). Expression of transcription factor, tailless, is required for formation of superficial cortical layers. Cereb. Cortex., 13, 921-931.

Larkman, A. \& Mason, A. (1990) Correlations between morphology and electrophysiology of pyramidal neurons in slices of rat visual cortex. I. Establishment of cell classes. J. Neursoci., 10, 1407-1414.

Lee, J.E. (1997) Basic helix-loop-helix genes in neural development. Curr. Opin. Neurobiol., 7, 13-20.

Lee, S.K. \& Pfaff, S.L. (2003) Synchronization of neurogenesis and motor neuron specification by direct coupling of bHLH and homeodomain transcription factors. Neuron, 38, 731-745.

Letinic, K., Zoncu, R. \& Rakic, P. (2002) Origin of GABAergic neurons in the human neocortex. Nature, 417, 645-649.

Lo, L., Dormand, E., Greenwood, A. \& Anderson, D.J. (2002) Comparison of the generic neuronal differentiation and neuron subtype specification functions of mammalian achaete-scute and atonal homologs in cultured neural progenitor cells. Development, 129, 1553-1567.

Lukaszewicz, A., Savatier, P., Cortay, V., Giroud, P., Huissoud, C., Berland, M., Kennedy, H. \& Dehay, C. (2005) G1 phase regulation, area-specific cell cycle control, and cytoarchitectonics in the primate cortex. Neuron, 47, 323-325.

Luskin, M.B., Pearlman, A.L. \& Sanes, J.R. (1988) Cell lineage in the cerebral cortex of the mouse studied in vivo and in vitro with a recombinant retrovirus. Neuron, 1, 635-647.

Ma, Q., Kintner, C. \& Anderson, D.J. (1996) Identification of neurogenin, a vertebrate neuronal determination gene. Cell, 87, 43-52.

Mackarehtschian, K., Lau, C.K., Caras, I. \& McConnell, S.K. (1999) Regional differences in the developing cerebral cortex revealed by ephrin-A5 expression. Cereb. Cortex, 9, 601-610.

Malatesta, P., Hack, M.A., Hartfuss, E., Kettenmann, H., Klinkert, W., Kirchhoff, F. \& Götz, M. (2003) Neuronal or glial progeny: regional differences in radial glial fate. Neuron, 37, 751-764.

Malatesta, P., Hartfuss, E. \& Götz, M. (2000) Isolation of radial glia cells by fluorescent-activated cell sorting reveals a neuronal lineage. Development, 127, 5253-5263.

Mallamaci, A. \& Stoykova, A. (2006) Gene networks controlling early cerebral cortex arealization. Eur. J. Neurosci., 23, 847-856.

Marin, O. \& Rubenstein, J.L. (2001) A long, remarkable journey: tangential migration in the telencephalon. Nat. Rev. Neurosci., 2, 780-790.

Markram, H. (2004) Correlation maps allow neuronal electrical properties to be predicted from single-cell gene expression profiles in rat neocortex. Cereb. Cortex, 14, 1310-1327. 
Marshall, C.A., Suzuki, S.O. \& Goldman, J.E. (2003) Gliogenic and neurogenic progenitors of the subventricular zone: who are they, where did they come from, and where are they going? Glia, 43, 52-61.

McCarthy, M., Turnbull, D.H., Walsh, C.A. \& Fishell, G. (2001) Telencephalic neural progenitors appear to be restricted to regional and glial fates before the onset of neurogenesis. J. Neurosci., 21, 6772-6781.

McConnell, S.K. (1988) Fates of visual cortical neurons in the ferret after isochronic and heterochronic transplantation. J. Neurosci., 8, 945-974.

McConnell, S.K. (1995) Constructing the cerebral cortex: neurogenesis and fate determination. Neuron, 15, 761-768.

McEvilly, R.J., de Diaz, M.O., Schonemann, M.D., Hooshmand, F. \& Rosenfeld, M.G. (2002) Transcriptional regulation of cortical neuron migration by POU domain factors. Science, 295, 1528-1532.

Miller, M.W. (1998) Development of projection and local circuit neurons in neocortex. In Peters, A. \& Jones, E. (eds), Cerebral Cortex: Development Maturation of Cerebral Cortex. Plenum Press, New York, London, pp. 133175.

Miyata, T., Kawaguchi, A., Okano, H. \& Ogawa, M. (2001) Asymmetric inheritance of radial glial fibers by cortical neurons. Neuron, 13, 727741.

Miyata, T., Kawaguchi, A., Saito, K., Kawano, M., Muto, T. \& Ogawa, M. (2004) Asymmetric production of surface-dividing and non-surface-dividing cortical progenitor cells. Development, 131, 3133-3145.

Mizuguchi, R., Sugimori, M., Takebayashi, H., Kosako, H., Nagao, M., Yoshida, S., Nabeshima, Y., Shimamura, K. \& Nakafuku, M. (2001) Combinatorial roles of olig2 and neurogenin2 in the coordinated induction of pan-neuronal and subtype-specific properties of motoneurons. Neuron, 31, 757-771.

Molnár, Z. \& Cheung, A.F.P. (2006) Towards the classification of subpopulations of layer $\mathrm{V}$ pyramidal projection neurons. Neurosci. Res., in press.

Molyneaux, B.J., Arlotta, P., Hirata, T., Hibi, M. \& Macklis, J.D. (2005) FezI is required for the birth and specification of corticospinal motor neurons. Neuron, 47, 817-831.

Morrow, T., Song, M.R. \& Ghosh, A. (2001) Sequential specification of neurons and glia by developmentally regulated extracellular factors. Development, 128, 3585-3594.

Mutoh, H., Naya, F.J., Tsai, M.J. \& Leiter, A.B. (1998) The basic helix-loophelix protein BETA2 interacts with p300 to coordinate differentiation of secretin-expressing enteroendocrine cells. Genes Dev., 12, 820-830.

Muzio, L., DiBenedetto, B., Stoykova, A., Boncinelli, E., Gruss, P. \& Mallamaci, A. (2002a) Emx2 and Pax6 control regionalization of the preneuronogenic cortical primordium. Cereb. Cortex, 12, 129-139.

Muzio, L., DiBenedetto, B., Stoykova, A., Boncinelli, E., Gruss, P. \& Mallamaci, A. (2002b) Conversion of cerebral cortex into basal ganglia in Emx2 (-/-/Pax6(SeySey) double mutant mice. Nat. Neurosci., 5, 737745 .

Nakashima, K., Yanagisawa, M., Arakawa, H., Kimura, N., Hisatsune, T., Kawabata, M., Miyazono, K. \& Taga, T. (1999) Synergistic signaling in fetal brain by STAT3-Smad1 complex bridged by p300. Science, 284, 479-482.

Nieto, M., Schuurmans, C., Britz, O. \& Guillemot, F. (2001) Neural bHLH genes control the neuronal versus glial fate decision in cortical progenitors. Neuron, 29, 401-413.

Nieto, M. Monuki, E.S., Tang, H., Imitola, J., Haubst, N., Khoury, S.J., Cunningham, J., Gotz, M. \& Walsh, C.A. (2004) Expression of Cux-1 and Cux-2 in the subventricular zone and upper layers II-IV of the cerebral cortex. J. Comp. Neurol., 479, 168-180.

Noctor, S.C., Martinez-Cerdeno, V., Ivic, L. \& Kriegstein, A.R. (2004) Cortical neurons arise in symmetric and asymmetric division zones and migrate through specific phases. Nat. Neurosci., 7, 136-144.

Parras, C.M., Galli, R., Britz, O., Soares, S., Galichet, C., Battiste, J., Johnson, J.E., Nakafuku, M., Vescovi, A.L. \& Guillemot, F. (2004) Mash1 specifies neurons and oligodendrocytes in the postnatal brain. EMBOJ., 23, 4495-4505.

Peters, A. \& Jones, E.G., Eds. (1985) Cerebral Cortex: Vol. 3, Visual Cortex; Vol. 4, Association and Auditory Cortices. Plenum Press, New York, London.

Polleux, F., Dehay, C., Moraillon, B. \& Kennedy, H. (1997) Regulation of neuroblast cell-cycle kinetics plays a crucial role in the generation of unique features of neocortical areas. J. Neurosci., 17, 7763-7783.

Price, J., Williams, B.P. \& Gotz, M. (1995) The generation of cellular diversity in the cerebral cortex. Ciba Found. Symp, 193, 71-84.

Qian, X., Shen, Q., Goderie, S.K., He, W., Capela, A., Davis, A.A. \& Temple, S. (2000) Timing of CNS cell generation: a programmed sequence of neuron and glial cell production from isolated murine cortical stem cells. Neuron, 28, 69-80.

Reid, C.B., Liang, I. \& Walsh, C. (1995) Systematic widespread clonal organization in cerebral cortex. Neuron, 15, 299-310.
Rolph, R., Cheung, A.F.P., Voelker, C.C.J., Jessell, T. \& Molnár, Z. (2005) ER81 and N200 reveals separate subpopulations of layer V pyramidal projection neurons (Abstract). British Neuroscience Association Meeting, Brighton.

Ross, S.E., Greenberg, M.E. \& Stiles, C.D. (2003) Basic helix-loop-helix factors in cortical development. Neuron, 39, 13-25.

Scardigli, R., Baumer, N., Gruss, P., Guillemot, F. \& Le Roux, I. (2003) Direct and concentration-dependent regulation of the proneural gene Neurogenin2 by Pax6. Development, 130, 3269-3281.

Schmahl, W., Knoedlseder, M., Favor, J. \& Davidson, D. (1993) Defects of neuronal migration and the pathogenesis of cortical malformations are associated with Small eye (Sey) in the mouse, a point mutation at the Pax-6locus. Acta Neuropathol., 86, 126-135.

Schuurmans, C., Armant, O., Nieto, M., Stenman, J.M., Britz, O., Klenin, N., Seibt, J., Brown, C., Tang, H., Cunningham, J.M., Dyck, R., Walsh, C., Campbell, K., Polleux, F. \& Guillemot, F. (2004) Sequential phases of neocortical fate specification involve Neurogenin-dependent and -independent pathways. EMBO J., 23, 2892-2902.

Schwindt, P.C. \& Crill, W.E. (1997) Modification of current transmitted from apical dendritic to soma by blockade of voltage- and Ca2+-dependent conductances in rat neocortical pyramidal neurons. J. Neurophysiol., 78, $187-198$.

Shirasaki, R. \& Pfaff, S.L. (2002) Transcriptional codes and the control of neuronal identity. Annu. Rev. Neurosci., 25, 251-281.

Sidman, R.L. \& Rakic, P. (1973) Neuronal migration, with special reference to developing human brain: a review. Brain Res., 62, 1-35.

Simpson, T.I. \& Price, D.J. (2002) Pax6; a pleiotropic player in development. Bioessay, 24, 1041-1051.

Smart, I.H.M., Dehay, C., Giroud, P., Berland, M. \& Kennedy, M. (2002) Unique morphological features of the proliferative zones and postmitotic compartments of the neural epithelium giving rise to striate and extrastriate cortex in the monkey. Cereb. Cortex, 12, 37-53.

Smart, I.H. \& McSherry, G.M. (1982) Growth patterns in the lateral wall of the mouse. II. Histological changes during and subsequent to the period of isocortical neuron production. J. Anat., 134, 415-442.

Smart, I.H. \& Smart, M. (1982) Growth patterns in the lateral wall of the mouse telencephalon. I. Autoradiographic studies of the histogenesis of the isocortex and adjacent areas. J. Anat., 134, 273-298.

Stenman, J.M., Yu, R.T., Evans, R.M. \& Campbell, K. (2003) Tlx and Pax6 co-operate genetically to establish the pallio-subpallial boundary in the embryonic mouse telencephalon. Development, 130, 1113-1122.

Stoykova, A., Fritsch, R., Walther, C. \& Gruss, P. (1996) Forebrain patterning defects in Small eye mutant mice. Development, 122, 3453-3465.

Stoykova, A., Götz, M., Gruss, P. \& Price, J. (1997) Pax6-dependent regulation of adhesive patterning, R-cadherin expression and boundary formation in developing forebrain. Development, 124, 3765-3777.

Stoykova, A. \& Gruss, P. (1994) Roles of Pax-genes in developing and adult brain as suggested by expression patterns. J. Neurosci., 14, 1395-1412.

Stoykova, A., Treichel, D., Hallonet, M. \& Gruss, P. (2000) Pax6 modulates the dorsoventral patterning of the mammalian telencephalon. J. Neurosci., 20, $8042-8050$.

Sugino, K., Hempel, C.M., Miller, M.N., Hattox, A.M., Shapiro, P., Wu, C., Huang, Z.J. \& Nelson, S.B. (2006) Molecular taxonomy of major neuronal classes in the adult mouse forebrain. Nat. Neurosci., 9, 99-107.

Sugitani, Y., Nakai, S., Minowa, O., Nishi, M., Jishage, K., Kawano, H., Mori, K., . Ogawa, M. \& Noda, T. (2002) Brn-1 and Brn-2 share crucial roles in the production and positioning of mouse neocortical neurons. Genes Dev., 16, 1760-1765.

Sun, Y., Nadal-Vicens, M., Misono, S., Lin, M.Z., Zubiaga, A., Hua, X., Fan, G. \& Greenberg, M.E. (2001) Neurogenin promotes neurogenesis and inhibits glial differentiation by independent mechanisms. Cell, 104, 365-376.

Suzuki, S.C., Inoue, T., Kimura, Y., Tanaka, T. \& Takeichi, M. (1997) Neuronal circuits are subdivided by differential expression of type-II classic cadherins in postnatal mouse brains. Mol. Cell Neurosci., 9, 433-447.

Tarabykin, V., Stoykova, A., Usman, N. \& Gruss, P. (2001) Cortical upper layer neurons derive from the subventricular zone as indicated by Svet1 gene expression. Development, 127, 2537-2548.

Tekki-Kessaris, N., Woodruff, R., Hall, A.C., Gaffield, W., Kimura, S., Stiles, C.D., Rowitch, D.H. \& Richardson, W.D. (2001) Hedgehog-dependent oligodendrocyte lineage specification in the telencephalon. Development, 128, 2545-2554.

Temple, S. (2001) The development of neural stem cells. Nature, 414, 112-117.

Thomas, J.L., Spassky, N., Perez Villegas, E.M., Olivier, C., Cobos, I., Goujet-Zalc, C., Martinez, S. \& Zalc, B. (2000) Spatiotemporal 
development of oligodendrocytes in the embryonic brain. J. Neurosci. Res., 59, 471-476.

Tole, S., Remedios, R., Saha, B. \& Stoykova, A. (2005) Selective requirement of Pax6, but not Emx2, in the specification and development of several nuclei of the amygdaloid complex. J. Neurosci., 25, 2753-2760.

Tomita, K., Moriyoshi, K., Nakanishi, S., Guillemot, F. \& Kageyama, R. (2000) Mammalian achaete-scute and atonal homologs regulate neuronal versus glial fate determination in the central nervous system. EMBO J., 19, 5460-5472.

Toresson, H., Potter, S.S. \& Campbell, K. (2000) Genetic control of dorsalventral identity in the telencephalon: opposing roles for Pax6 and Gsh2. Development, 127, 4361-4371.

Treisman, J., Harris, E. \& Desplan, C. (1991) The paired box encodes a second DNA-binding domain in the paired homeo domain protein. Genes Dev., $\mathbf{5}$, 594-604.

Tsiola, A., Hamzei-Sichani, F., Peterlin, Z. \& Yuste, R. (2003) Quantitative morphologic classification of layer 5 neurons from mouse primary visual cortex. J. Comp. Neurol., 461, 415-428.

Voelker, C.C., Garin, N., Taylor, J.S., Gahwiler, B.H., Hornung, J.P. \& Molnar, Z. (2004) Selective neurofilament (SMI-32, FNP-7 and N200) expression in subpopulations of layer $\mathrm{V}$ pyramidal neurons in vivo and in vitro. Cereb. Cortex, 14, 1276-1286.

Walther, C. \& Gruss, P. (1991) Pax-6, a murine pared box gene, is expressed in the developing CNS. Development, 113, 1435-1449.
Warren, N., Caric, D., Pratt, T., Clausen, J.A., Asavaritikrai, P., Mason, J.O., Hill, R.E. \& Price, D.J. (1999) The transcription factor, Pax6, is required for cell proliferation and differentiation in the developing cerebral cortex. Cereb. Cortex, 9, 627-635.

Weimann, J.M., Zhang, Y.A., Levin, M.E., Devine, W.P., Brulet, P. \& McConnell, S.K. (1999) Cortical neurons require Otx1 for the refinement of exuberant axonal projections to subcortical targets. Neuron, 24, 819-831.

Williams, B.P. \& Price, J. (1995) Evidence for multiple precursor cell types in the embryonic rat cerebral cortex. Neuron, 14, 1181-1188.

Yoneshima, H., Yamasaki, S., Voelker, C.C., Molnár, Z., Christophe, E., Audinat, E., Takemoto, M., Nishiwaki, M., Tsuji, S., Fujita, I. \& Yamamoto, N. (2006) ER81 is expressed in a subpopulation of layer 5 projection neurons in rodent cerebral cortices. Neuroscience, 137, 401-412.

Yun, K., Potter, S. \& Rubenstein, J.L. (2001) Gsh2 and Pax6 play complimentary roles in dorsoventral patterning of the mammalian telencephalon. Development, 128, 193-205.

Zhong, Y., Takemoto, M., Fukuda, T., Hattori, Y., Murakami, F., Nakajima, D., . Nakayama, M. \& Yamamoto, N. (2004) Identification of the genes that are expressed in the upper layers of the neocortex. Cereb. Cortex, 14, 1144 1152.

Zimmer, C., Tivceron, M.-C., Bodmer, R. \& Cremer, H. (2004) Dynamics of Cux2 expression suggests that an early pool of SVZ precursors is fated to become upper cortical layer neurons. Cereb. Cortex, 14, 1408-1420. 